\title{
Chemical Synthesis of Human Selenoprotein F and Elucidation of Its Thiol-Disulfide Oxidoreductase Activity
}

\author{
Peisi Liao ${ }^{a}$, Hongmei Liu ${ }^{\text {bc* }}$ and Chunmao $\mathrm{He}^{\mathrm{a}^{*}}$ \\ Selenoprotein F (SeIF) is an endoplasmic reticulum-residing eukaryotic protein that contains a selenocysteine (Sec) residue. \\ It has been suggested to be involved in a number of physiological processes by acting as a thiol-disulfide oxidoreductase, \\ but the exact role has remained unclear due to the lack of a reliable production method. We document herein a robust \\ synthesis of the human SelF through a three-segment two-ligation semisynthesis strategy. Highlighted in this synthetic \\ route are the use of a mild desulfurization process to protect the side-chain of the Sec residue from being affected and the \\ simultaneous removal of acetamidomethyl and $p$-methoxybenzyl protection groups by $\mathrm{PdCl}_{2}$, thus facilitating the synthesis \\ of multi-milligram of homogenous SelF. The reduction potential of SelF was determined and the thiol-disulfide \\ oxidoreductase activity was further supported by its ability to catalyze the reduction and isomerization of disulfide bonds.
}

\section{Introduction}

Selenoprotein $F($ SelF), or the $15-k D a$ protein (Sep15), is an endoplasmic reticulum (ER)-residing eukaryotic protein containing the $21^{\text {st }}$ essential (proteinogenic) amino acid selenocysteine (Sec, U). ${ }^{1}$ An increasing number of studies have linked SelF gene polymorphisms and SelF dysregulation to various diseases, including several types of cancer, AIDS, and neurodegeneration, which reveals the importance of SelF's physiological functions. ${ }^{2}$ As shown in Figure $1 \mathrm{~A}$, the mature human SelF consists of 134 amino acid residues (aa), including an $\mathrm{N}$-terminal Cys-rich domain and a C-terminal thioredoxin (Trx)-like domain. Although with no typical ER retention peptide sequence, SelF is able to bind the UDP-glucose: glycoprotein glucosyltransferase (UGGT) - a large chaperone protein in the ER, via its $\mathrm{N}$-terminal Cys-rich domain, thus also called the UGGT binding domain; ${ }^{3}$ The C-terminal Trx-like domain contains a unique CGU redox motif in a dynamic loop, a key structure rendering SelF a competent thiol-disulfide oxidoreductase in the ER. ${ }^{4}$ As such, SelF has been suggested to play a role in the quality control of the ER, by either rearranging (isomerase function) or reducing incorrectly formed disulfide bonds (reductase function) in misfolded glycoproteins bound to UGGT, ${ }^{5,6}$ but its exact biological function is yet to be elucidated. Along this line, the in vitro characterization of SelF is generally missing due to the lack of reliable recombinant expression technique, and most studies are carried out with its Sec-to-Cys homologue. ${ }^{4}$ In this context, the disulfide pairing mode of SelF(U65C) has been elucidated in our previous work through site-directed mutagenesis and enzymatic digestion (see Figure 1B), ${ }^{7}$ the clear evidence of a selenenylsulfide bond in the CGU motif is, however, still

\footnotetext{
a. School of Chemistry and Chemical Engineering, South China University of Technology, Guangzhou 510640, China. Email: hecm@scut.edu.cn.

${ }^{b}$. Hubei Key Laboratory of Bioinorganic Chemistry and Materia Medica, School of Chemistry and Chemical Engineering, Huazhong University of Science and

Technology, Wuhan 430074, China. Email: hongmeiliuhust@hust.edu.cn.

c. Shenzhen Huazhong University of Science and Technology Research Institute,

Shenzhen 518057, China

Electronic Supplementary Information (ESI) available.
}

lacking. Notably, a few examples have been reported using the genetic code expansion technology to incorporate Sec sitespecifically. ${ }^{8-11}$

Chemical protein synthesis (CPS), enabled by chemoselective peptide ligation reactions like the native chemical ligation (NCL), ${ }^{12,13}$ has contributed a large number of synthetic proteins which easily incorporate non-natural amino acids or protein modifications. ${ }^{14,15}$ The development of expressed protein ligation (EPL) technologies has further powered the synthesis of (especially) large proteins. ${ }^{16,17}$ A number of native selenoproteins and Sec-containing analogue proteins have thus been generated by CPS, as listed in Table S1. ${ }^{18-29}$ Despite these significant achievements, the currently used synthetic routes usually involve either no or limited post-ligation treatment, as a result most of the synthetic Sec-proteins either are small in size (usually $<100$ aa and with few Cys/Sec residues) or contain a Sec residue at the C-terminal region, which can be obtained by EPL through ligation with a synthetic peptide bearing an $\mathrm{N}$-terminus Sec (Table S1, Entries 4, 8 and 11). As such, there is a clear need to develop a more straightforward strategy for the synthesis of complex selenoproteins having multiple Cys and Sec residues, like in the case of SelF (7 Cys and $1 \mathrm{Sec}$ ).

We disclose herein the synthesis of SelF, where the Sec65 residue resides in the middle of its sequence, making it inconvenient to apply EPL. To maximize the overall synthetic yield, we adopted a three-segment two-ligation strategy, where Ala75 was chosen as one of the ligation sites as there is no Cys available in the C-terminal region, and a desulfurization step will be required (Figure 1B). While selective deselenization in the presence of Cys has been routinely carried out using tris(2-carboxyethyl)phosphine (TCEP), ${ }^{30,}{ }^{31}$ the selective desulfurization in the presence of Sec has not been reported to the best of our knowledge, which is one of the key challenges in our synthetic endeavor. With the current strategy, multi-milligram of homogeneous synthetic SelF was obtained, which allowed the elucidation of its thiol-disulfide oxidoreductase activity, thus providing evidences for its involvement in the quality control of the ER. 


\section{Results and discussion}

\section{Synthetic strategy}

In analogy to the synthesis of the SelF(U65C) analogue, ${ }^{7}$ the full-length protein was disconnected into three segments at Gly41-Cys42 and GIn74-Ala75. Noted that the Gln74 was mutated to an Ala residue in order to obtain a stable peptide hydrazide segment, and according to previous experience ${ }^{7}$ this mutation should not affect the protein folding and function (vide infra). Unlike most of the reported synthetic Seccontaining proteins where the Sec residue is placed in the $\mathrm{N}$ terminus of the peptide, i.e. the ligation site, we opted to place it as an internal residue in segment $\mathbf{2}$ and the side-chain was protected with a p-methoxybenzyl (Mob) group. Moreover, the Cys75 residue of segment 3 will have to be desulfurized to give the native Ala residue, and for this purpose, all the Cys residues in segment $\mathbf{2}$ were protected with an acetamidomethyl (Acm) group, which also prevents the lactamization of the resulting thioester. As such, segments 1 and $\mathbf{2}$ were obtained with standard Fmoc-SPPS, and segment 3 through $\mathrm{N}$-terminal His-SUMO fusion protein expression and Ulp1 cleavage. ${ }^{32,33}$

\section{(A) Amino acid sequence of $\operatorname{SelF}(Q 74 A)$ :}

FGAEFSSEAC ${ }^{10} R$ ELGFSSNLL CSSCDLLGQF NLLQLDPDCR G-C ${ }^{42} C Q$ EEAQFE TKKLYAGAIL EVCGU ${ }^{65}$ KLGRF PQVA-A ${ }^{75}$ FVRSD KPKLFRGLQ I KYVRGSDPVL KLLDDNGNIA EELSILKWNT DSVEEFLSEK L ERI ${ }^{134}$

(B) Retrosynthesis of SelF(Q74A): UGGT-binding domain

Trx-like domain
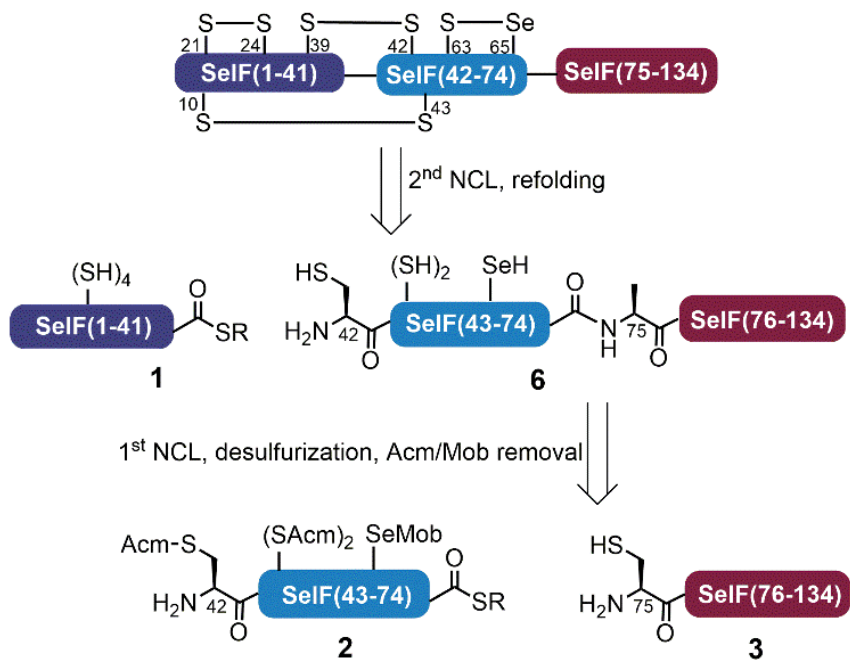

Figure 1. (A) Sequence of the human SelF(Q74A). The red and green underlined areas are UGGT-binding domain and Trx-like domain, respectively. The pseudoproline dipeptides used were in italic. (B) Retrosynthesis strategy.

\section{Chemical synthesis of SelF and its Trx-like domain}

With all peptide segments in hands, the first NCL reaction was carried out between segments $\mathbf{2}$ and $\mathbf{3}$, which completed within $2 \mathrm{~h}$ (Figure 2). At this stage, the initial plan for a one-pot desulfurization at Cys 75 failed due to the increased amount of 2,2'-Azobis[2-(2-imidazolin-2-yl)propane]dihydrochloride (VA044) required in this case (vide infra). Instead, peptide 4 was purified and subjected to standard desulfurization conditions (i.e. $30-40$ eq VA-044, $200 \mathrm{mM}$ TCEP and $5 \% t$-BuSH) $(t$-BuSH $=$ tert-butylthiol). ${ }^{34}$ Surprisingly, the unwanted peptide $\mathbf{5}^{\prime}$ with desulfurization at Cys75 and deselenization at Sec65-despite being Mob-protected, was the major product (Figures S13-14). The peptide $\mathbf{S 2}$ (the hydrazide precursor of segment $\mathbf{2}$ ) was then used as a model peptide and its stability was tested against each desulfurization component, and no significant change was observed when incubating with TCEP or $t$-BuSH (Figures S15-16), which led us to conclude that VA-044 could most probably be the reason.

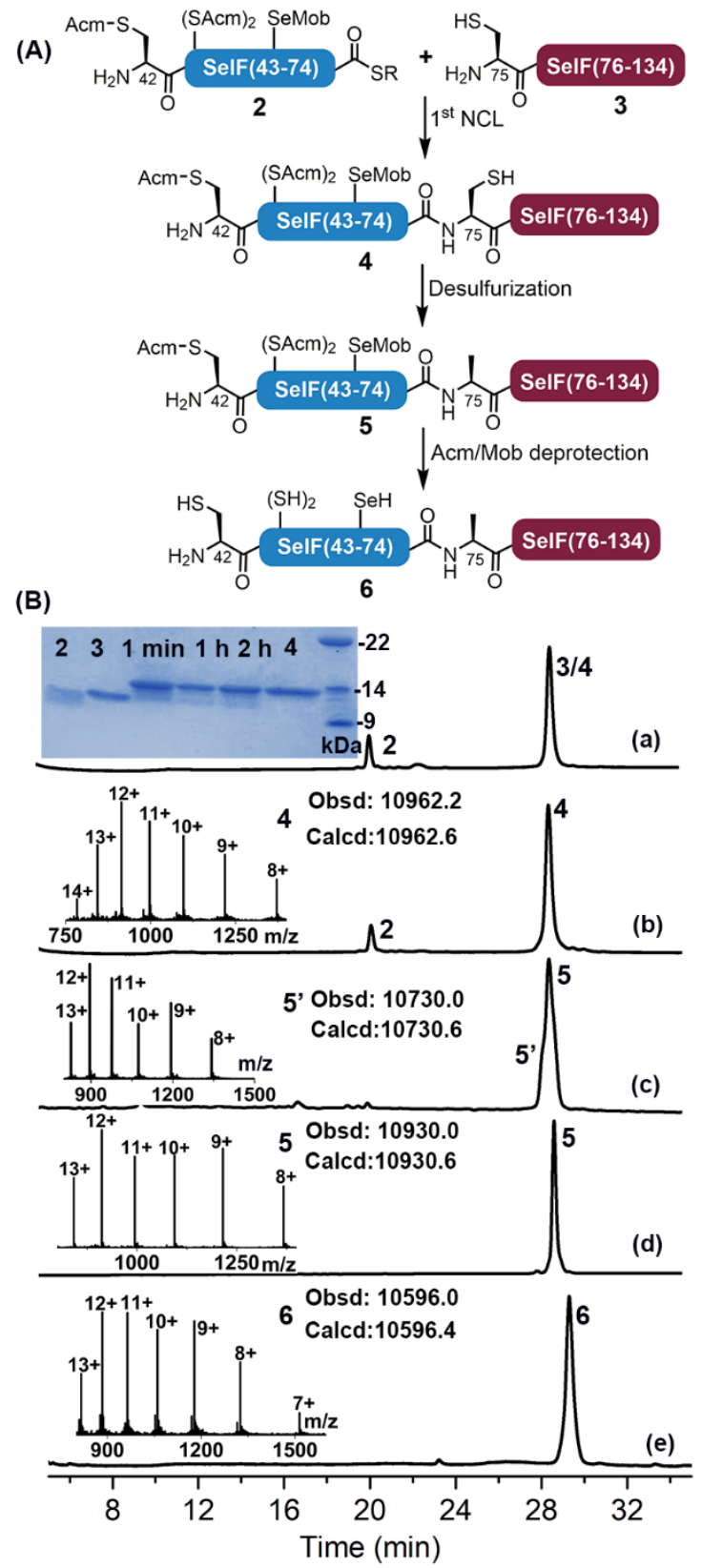

Figure 2. (A) Scheme for the synthesis of the peptide 6. (B) (a-b) Analytical HPLC traces of $\mathrm{NCL}$ at $1 \mathrm{~min}$ and $2 \mathrm{~h}$, respectively. Inset a: SDS-PAGE analysis of the ligation reaction. Inset b: ESI-MS of peptide 4. (c) Analytical HPLC trace of desulfurization at $30 \mathrm{~min}$ and ESI-MS of the by-product 5'. (d) Analytical HPLC trace and ESI-MS of purified 5. (e) HPLC trace of $\mathrm{PdCl}_{2}$-mediated $\mathrm{Acm} / \mathrm{Mob}$ removal in $2 \mathrm{~h}$ and ESI-MS of the product 6 .

To our delight, when reducing the amounts of VA-044 (to 2.5 eq), the desired desulfurized peptide $\mathbf{5}$ was obtained as the 
major product at $30 \mathrm{~min}$, with an isolated yield of $39.5 \%$ (Figure S22). ${ }^{35}$ It seems that the presence of the Mobprotected Sec residue in the sequence speeded up the desulfurization, as the same process would usually take longer (4-24 h) and need more VA-044 (e.g. 50 eq.) in the Cyscontaining homologue peptide. ${ }^{7}$

Next, the global Acm removal of peptide $\mathbf{5}$ was attempted, and the Mob group of Sec65 was supposed to be retained at this stage to prevent possible deselenizaiton in the following $\mathrm{NCL}$. While the Acm-removal with AgOAc went well during the synthesis of SelF(U65C), ${ }^{7}$ it gave a complex mixture in this case, with all Acm and Mob groups being removed as well as severe peptide truncation (Figures S24-S25). We then switched to the $\mathrm{PdCl}_{2}$-dithiothreitol (DTT) method, ${ }^{36,37}$ and by accident we noticed that an increased amount of $\mathrm{Pd}^{2+}$ could lead to a simultaneous Acm and Mob removal of a model peptide S5 (Figures S26-S27). It is worth noting that there is literature presence using $\mathrm{Pd}^{0}$ for the deprotection of an allyl group from $\mathrm{Sec}$ in aqueous solution. ${ }^{38}$ Gratifyingly, when using 150 eq of $\mathrm{PdCl}_{2}$ quantitative global $\mathrm{Acm} / \mathrm{Mob}$ removal of peptide 5 was accomplished (Figure S29), subsequently, the excess Pd reagent was removed by DTT and extensive washing, which after incubation with ascorbate and TCEP to reduce any possible peptide diselenide dimer afforded peptide 6 . The discovery that the Mob group can be facilely removed by aqueous $\mathrm{PdCl}_{2}$ solution is remarkable considering the generally harsh conditions required in the literature procedures, ${ }^{39,40}$ like the use of dimethyl sulfoxide (DMSO) ${ }^{41}$ or 2,2'-dithiobis(5nitropyridine) (DTNP) ${ }^{42,43}$ in TFA. We envision that the chemistries relating to the selective desulfurization in the presence of Sec and simultaneous Acm/Mob removal disclosed herein may find further applications in the CPS field, where the use of Sec either for selenoprotein synthesis or as a Cys analogue, has become an increasingly popular strategy. ${ }^{28,31,44}$ 45

The second ligation between peptide 1 and $\mathbf{6}$ was carried out in the presence of $0.1 \mathrm{M}$ ascorbate and a reduced concentration of TCEP $(5 \mathrm{mM})$ to prevent the now-free selenol side-chain from being removed, ${ }^{46-48}$ furnishing the full-length protein 7. After $12 \mathrm{~h}$, the ligation mixture was directly subjected to the redox refolding buffer, and the refolded protein $\mathbf{8}$ was obtained after HPLC purification with an isolated yield of $13.7 \%$ over two steps $(\sim 1.5 \mathrm{mg})$. Noted that the presence of thiolactone derivative of peptide 1 (indicated with * in Figure 3) was probably one of the reasons for the slow ligation rate and the slightly lowered recovery yield. In principle installation of Acm protection group at the Cys sidechain during the synthesis of peptide $\mathbf{1}$ could avoid the formation of thiolactone, we have, however, observed significant aspartimide formation at the Asp-Cys(Acm) sequence (data not shown), as also reported in the literature. ${ }^{49}$ Nevertheless, with the current route enough amounts of protein was obtained for further studies, and the residual Pdcontent in $\mathbf{8}$ determined using ICP-MS was negligible $(<0.061 \%)$. The proper folding of $\mathbf{8}$ was confirmed by ESI-MS ( -8 Da vs. 7) and the CD spectrum (vs. the expressed Cys analogue ${ }^{7}$ ). And importantly, the presence of a mixed selenenylsulfide bond between Cys63-Sec65 was established via a consecutive trypsin/chymotrypsin digestion (Figure S47), which agrees well the reported NMR structure of the fruit fly Sep15 protein as well as the SelF(U65C) homologue (both with a disulfide bond instead). ${ }^{4,7}$
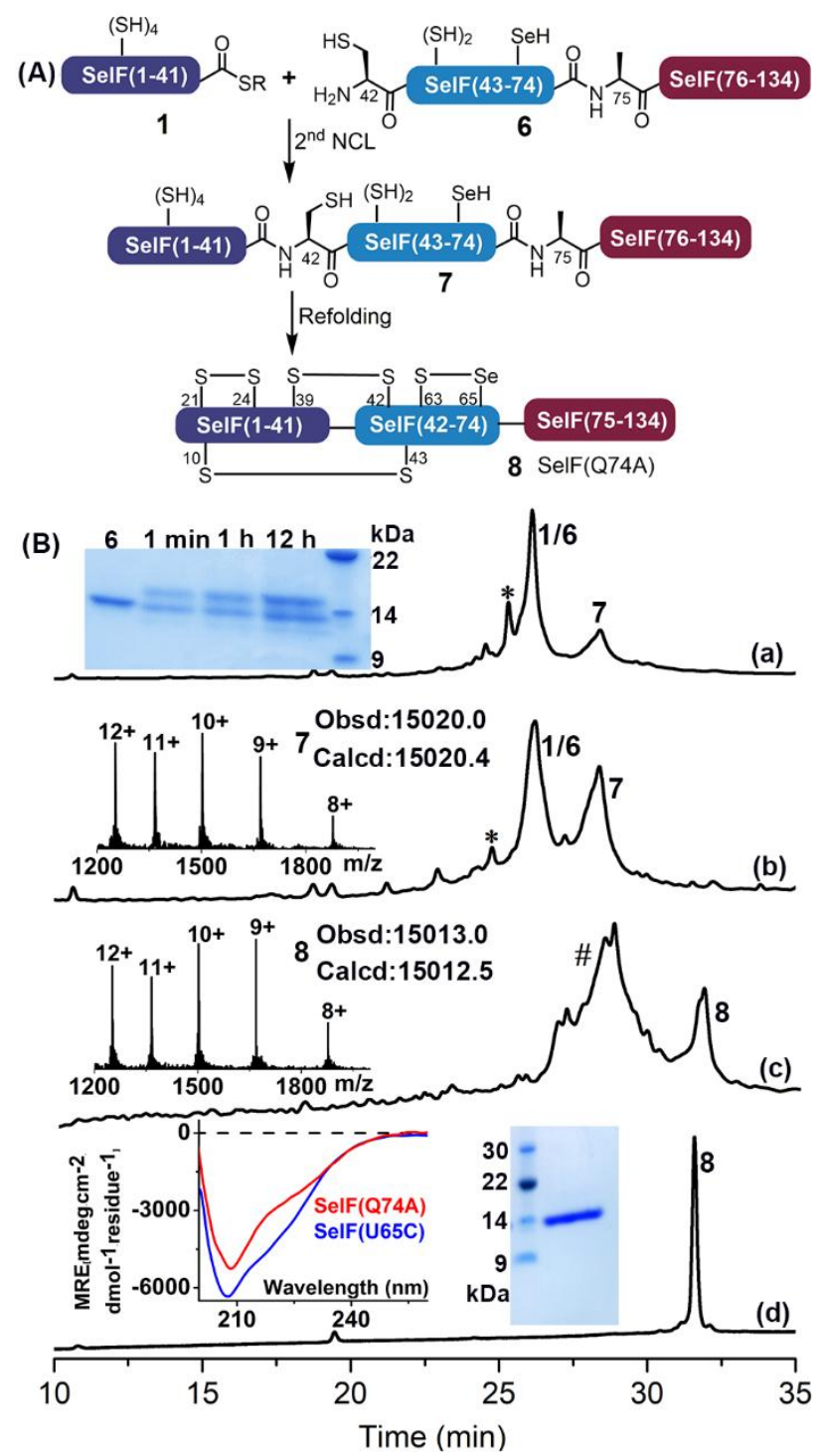

Figure 3. (A) Scheme for the second ligation and folding to afford the SelF(Q74A) (8). (B) (a-b) Analytical HPLC traces of ligation at $1 \mathrm{~min}$ and $12 \mathrm{~h}$, respectively. ${ }^{*}$ denotes the thiolactone derivative of peptide 1 . Inset a: SDS-PAGE analysis of the ligation reaction. Inset b: ESI-MS of 7. (c) Analytical HPLC trace of the refolding at $12 \mathrm{~h}$ and ESIMS of 8. \# denotes a mixture of hydrolyzed 1, unreacted peptide 6 and the misfolded by-products, etc. (d) Analytical HPLC trace of the purified 8. Inset: CD spectra of the synthetic SelF(Q74A) and the expressed SelF(U65C) (left), SDS-PAGE (right) of 8.

Meanwhile, following a similar synthetic strategy, e.g. NCL between a short $\mathrm{Sec}(\mathrm{Mob})$-containing peptide thioester segment S9 and segment $\mathbf{3}$, selective desulfurization, simultaneous $A c m / M o b$ removal and refolding, the Trx-like domain SelF(63-134)(Q74A) 9 was obtained conveniently (Figures S34-44), which set the stage for a comparative functional study with the full-length protein $\mathbf{8}$ (vide infra).

Probing of the thiol-disulfide reductase activity of SelF

With the synthetic protein in hand, it is now possible to determine its redox potential, a key parameter gauging its ability to act as a native thiol-disulfide oxidoreductase. ${ }^{50,51}$ 
Using a glutathione (GSH)-glutathione disulfide (GSSG) reference buffer, the fractions of the reduced SelF at selected GSH/GSSG ratios were measured by HPLC and plotted against the redox potential poised by the corresponding redox buffers (Figure 4A, Figure S50). The resulting data was fitted by Nernst equation and the potential of the SleF was established as -222 $\mathrm{mV}$, whereas the Cys homologue has a redox potential of -205 $\mathrm{mV}$. It agrees well with the reported value of the fruit fly Sep15 $(-225 \mathrm{mV})$, which has a disulfide rather than a selenenylsulfide in the active-site redox motif. ${ }^{4}$

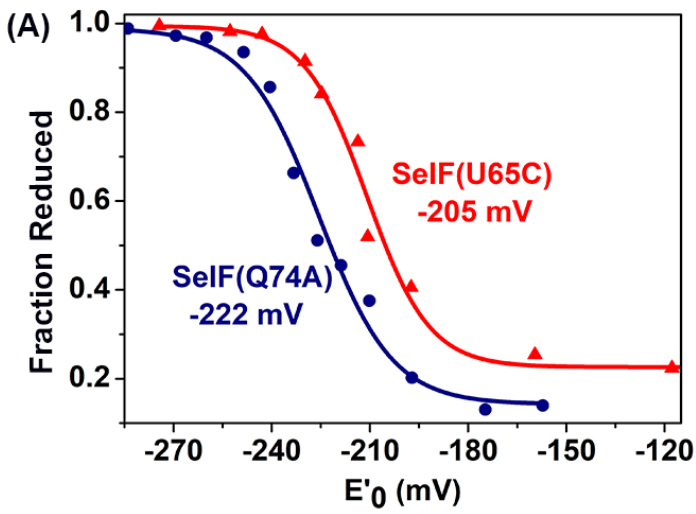

(B)
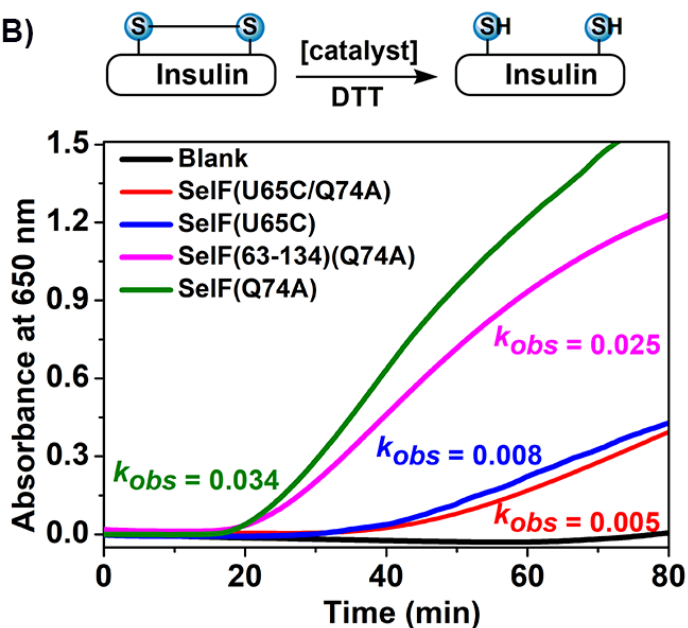

Figure 4. (A) Determination of the redox potentials of SelF(U65C) and SelF(Q74A). (B) Reductase activity assays via recording the turbidity caused by insulin's aggregation. Protein conc.: $2 \mu \mathrm{M}$

Encouraged by this result, we probed the thiol-disulfide oxidoreductase activities of the synthetic SelF protein. Firstly, the disulfide reductase activity was determined using insulin as a model substrate, ${ }^{52}$ where the cleavage of the disulfide bond connecting chain A and chain B will lead to protein aggregation and the resulting turbidity can be followed by absorption spectroscopy for assessment. As shown in Figure 4B and Figures S53-54, SelF leads to a quick increase of the turbidity (onset, $16 \mathrm{~min}$ ) with a $k_{\text {obs }}$ value of $0.034 \mathrm{~min}^{-1}$, whereas the Cys homologue SeIF(U65C) shows a much lower reaction rate (onset, $32 \mathrm{~min}$ and $k_{o b s}=0.008 \mathrm{~min}^{-1}$ ). It is worth noting that the double mutant SelF(U65C/Q74A) shows a similar, albeit low, reactivity compared to SelF(U65C), suggesting that the effect of mutation at this site $(G \ln 74)$ is minimum. Interestingly, the Trx-like domain of SelF 9, with the key CGU motif, is also active in reducing the disulfides of insulin. Altogether these data indicate that SleF is a viable disulfide reductase and the presence of Sec in the redox motif is clearly the key for this activity. Moreover, we also tested the protein disulfide isomerase activity of the synthetic SelF by assessing its ability to catalyze the refolding of the scrambled RNase A. As shown in Figure S57, only in the case of SelF a small but appreciable amount of folded RNase $A$ can be observed after $2 \mathrm{~h}$ incubation. While RNase A may not be the native substrate as presented in the ER, ${ }^{4}$ the current data suggests that SelF could indeed contribute in the isomerization of disulfide bonds of the (misfolded) glycoprotein substrates of UGGT.

\section{Conclusion}

In summary, we have developed a robust synthetic strategy affording the full-length human SelF protein that contains an internal Sec residue and seven other Cys residues. Notable challenges addressed in the synthetic route are 1 ) the use of a reduced amount of VA-044 during desulfurization to protect the side-chain of the Sec residue from being affected and 2) the simultaneous removal of Acm and Mob protection groups by $\mathrm{PdCl}_{2}$, thus facilitating the synthesis of multimilligram of homogenous SelF for biological studies. The critical selenenylsulfide bond Cys63-Sec65 in the CGU motif of SelF was unambiguously established, representing the first experimental evidence for such connectivity in SelF. The redox potential of the synthetic protein was determined to be -222 $\mathrm{mV}$, typical for those of the thiol-disulfide oxidoreductase. ${ }^{4,53}$, ${ }^{54}$ We demonstrate that SelF is capable of catalyzing the disulfide reduction and to a less extent, isomerisation, in vitro, and the Sec residue is the key for these functions. These data suggest that SelF, together with UGGT, can indeed play a crucial role in the quality control of ER. Moreover, the synthetic strategy developed herein may find broad applications in the synthesis of other complex selenoprotiens with multiple $\mathrm{Cys} / \mathrm{Sec}$ residues, and thus helping in the elucidation of their physiological functions.

\section{Author Contributions}

$\mathrm{PL}$ performed the experiments and wrote the manuscript. $\mathrm{HL}$ and $\mathrm{CH}$ conceptualized the project and revised the manuscript.

\section{Conflicts of interest}

There are no conflicts of interest to declare.

\section{Acknowledgements}

This work was supported by the National Natural Science Foundation of China (No. 22077040 to HL and Nos 91853117 and 22077036 to $\mathrm{CH}$ ), the Fundamental Research Funds for the Central Universities of SCUT (No. 2020ZYGXZR056) and the Shenzhen Fundamental Research Program (No. JCYJ20200109105836705). The technical assistance in ICP-MS from Ms. Shaomin Lin and Mr. Zhipeng Zhao was gratefully 
acknowledged. We also thank Dr. Yuqi Zhang and Mr. Zeyuan Mo for helpful discussion.

\section{Notes and References}

1 V. N. Gladyshev, K.-T. Jeang, J. C. Wootton and D. L. Hatfield, J. Biol. Chem., 1998, 273, 8910-8915.

2 B. Ren, M. Liu, J. Ni and J. Tian, Nutrients, 2018, 10, 1619.

3 V. M. Labunskyy, A. D. Ferguson, D. E. Fomenko, Y. Chelliah, D. L. Hatfield and V. N. Gladyshev, J. Biol. Chem., 2005, 280, 37839-37845.

4 A. D. Ferguson, V. M. Labunskyy, D. E. Fomenko, D. Araç, Y. Chelliah, C. A. Amezcua, J. Rizo, V. N. Gladyshev and J. Deisenhofer, J. Biol. Chem., 2006, 281, 3536-3543.

5 V. M. Labunskyy, D. L. Hatfield and V. N. Gladyshev, IUBMB Life, 2007, 59, 1-5.

6 V. M. Labunskyy, M.-H. Yoo, D. L. Hatfield and V. N. Gladyshev, Biochemistry, 2009, 48, 8458-8465.

7 P. Liao and C. He, Front. Chem., 2021, 9, 735149.

8 T. Mukai, A. Sevostyanova, T. Suzuki, X. Fu and D. Söll, Angew. Chem., Int. Ed., 2018, 57, 7215-7219.

9 R. Rakauskaitè, G. Urbanavičiūtè, A. Rukšènaitè, Z Liutkevičiūtè, R. Juškènas, V. Masevičius and S. Klimašauskas, Chem. Commun., 2015, 51, 8245-8248.

10 A. P. Welegedara, L. A. Adams, T. Huber, B. Graham and G. Otting, Bioconjug. Chem., 2018, 29, 2257-2264.

11 J. C. Peeler, J. A. Falco, R. E. Kelemen, M. Abo, B. V. Chartier, L. C. Edinger, J. Chen, A. Chatterjee and E. Weerapana, ACS Chem. Biol., 2020, 15, 1535-1540.

12 P. E. Dawson, T. W. Muir, I. Clark-Lewis and S. B. Kent, Science, 1994, 266, 776-779.

13 S. B. H. Kent, Chem. Soc. Rev., 2009, 38, 338-351.

14 V. Agouridas, O. El Mahdi, V. Diemer, M. Cargoët, J.-C. M. Monbaliu and O. Melnyk, Chem. Rev., 2019, 119, 7328-7443.

15 Y. Tan, H. Wu, T. Wei and X. Li, J. Am. Chem. Soc., 2020, 142, 20288-20298.

16 T. W. Muir, D. Sondhi and P. A. Cole, Proc. Natl. Acad. Sci., 1998, 95, 6705.

17 T. W. Muir, Annu. Rev. Biochem., 2003, 72, 249-289.

18 L. Dery, P. S. Reddy, S. Dery, R. Mousa, O. Ktorza, A. Talhami and N. Metanis, Chem. Sci., 2017, 8, 1922-1926.

19 N. J. Mitchell, J. Sayers, S. S. Kulkarni, D. Clayton, A. M. Goldys, J. Ripoll-Rozada, P. J. Barbosa Pereira, B. Chan, L. Radom and R. J. Payne, Chem, 2017, 2, 703-715.

20 B. Eckenroth, K. Harris, A. A. Turanov, V. N. Gladyshev, R. T. Raines and R. J. Hondal, Biochemistry, 2006, 45, 5158-5170.

21 N. Metanis, E. Keinan and P. E. Dawson, J. Am. Chem. Soc., 2006, 128, 16684-16691.

22 G. Casi, G. Roelfes and D. Hilvert, ChemBioChem, 2008, 9, 1623-1631.

23 R. J. Hondal, B. L. Nilsson and R. T. Raines, J. Am. Chem. Soc., 2001, 123, 5140-5141.

24 K. Medini, P. W. R. Harris, A. Menorca, K. Hards, G. M. Cook and M. A. Brimble, Chem. Sci., 2016, 7, 2005-2010.

25 R. Quaderer, A. Sewing and D. Hilvert, Helv. Chim. Acta, 2001, 84, 1197-1206.

26 N. Metanis and D. Hilvert, Chem. Sci., 2015, 6, 322-325.

27 S. M. Berry, M. D. Gieselman, M. J. Nilges, W. A. van der Donk and Y. Lu, J. Am. Chem. Soc. , 2002, 124, $2084-2085$.

28 Z. Zhao, D. Shimon and N. Metanis, J. Am. Chem. Soc., 2021, 143, 12817-12824.

29 Z. Zhao and N. Metanis, Angew. Chem., Int. Ed., 2019, 58 , 14610-14614.

30 N. Metanis, E. Keinan and P. E. Dawson, Angew. Chem., Int. Ed., 2010, 49, 7049-7053.

31 S. S. Kulkarni, E. E. Watson, B. Premdjee, K. W. CondeFrieboes and R. J. Payne, Nat. Protoc., 2019, 14, 2229-2257.
32 M. P. Malakhov, M. R. Mattern, O. A. Malakhova, M. Drinker, S. D. Weeks and T. R. Butt, J. Struct. Funct. Genomics, 2004, 5, 75-86.

33 A. Reif, S. Siebenhaar, A. Tröster, M. Schmälzlein, C. Lechner, P. Velisetty, K. Gottwald, C. Pöhner, I. Boos, V. Schubert, S. Rose-John and C. Unverzagt, Angew. Chem., Int. Ed., 2014, 53, 12125-12131.

34 Q. Wan and S. J. Danishefsky, Angew. Chem., Int. Ed., 2007, 46, 9248-9252.

35 As shown in Figure S20, the desulfurization of 4 works the best at $30 \mathrm{~min}$ in our hands, because the substrate 4 can still be observed at a shorter reaction time, e.g. $15 \mathrm{~min}$, and the deselenized side-product 5' can be observed when incubate longer, e.g. $1 \mathrm{~h}$.

36 S. K. Maity, M. Jbara, S. Laps and A. Brik, Angew. Chem., Int. Ed., 2016, 55, 8108-8112.

37 M. Jbara, S. Laps, M. Morgan, G. Kamnesky, G. Mann, C. Wolberger and A. Brik, Nat. Commun., 2018, 9, 3154.

38 J. Liu, F. Zheng, R. Cheng, S. Li, S. Rozovsky, Q. Wang and L. Wang, J. Am. Chem. Soc., 2018, 140, 8807-8816.

39 M. Muttenthaler and P. F. Alewood, J. Pept. Sci., 2008, 14, 1223-1239.

40 Z. Zhao and N. Metanis, J. Org. Chem., 2020, 85, 1731-1739.

41 T. Koide, H. Itoh, A. Otaka, H. Yasui, M. Kuroda, N. Esaki, K. Soda and N. Fujii, Chem. Pharm. Bull., 1993, 41, 502-506.

42 K. M. Harris, S. Flemer Jr and R. J. Hondal, J. Pept. Sci., 2007 13, 81-93

43 A. L. Schroll, R. J. Hondal and S. Flemer Jr, J. Pept. Sci., 2012 18, 155-162.

44 Z. Zhao, D. Shimon and N. Metanis, J. Am. Chem. Soc., 2021 143, 12817-12824

45 D. Lu, H. Yin, S. Wang, F. Tang, W. Huang and P. Wang, J. Org. Chem., 2020, 85, 1652-1660.

46 H. Rohde, J. Schmalisch, Z. Harpaz, F. Diezmann and O. Seitz ChemBioChem, 2011, 12, 1396-1400.

47 N. Ollivier, A. Blanpain, E. Boll, L. Raibaut, H. Drobecq and O. Melnyk, Org. Lett., 2014, 16, 4032-4035.

48 S. Dery, P. S. Reddy, L. Dery, R. Mousa, R. N. Dardashti and N. Metanis, Chem. Sci., 2015, 6, 6207-6212.

49 J. L. Lauer, C. G. Fields and G. B. Fields, Lett. Pept. Sci., 1995, 1, 197-205.

50 F. Åslund, K. D. Berndt and A. Holmgren, J. Biol. Chem., 1997, 272, 30780-30786.

51 J. Liu, F. Li and S. Rozovsky, Biochemistry, 2013, 52, 30513061.

52 A. Holmgren, J. Biol. Chem., 1979, 254, 9627-9632.

$53 \mathrm{~J}$. Lundstroem and A. Holmgren, Biochemistry, 1993, 32, 6649-6655.

54 E. Mössner, M. Huber-Wunderlich and R. Glockshuber, Protein Sci., 1998, 7, 1233-1244. 